\title{
Contribuição aos Hemilophini (Cerambycidae, Lamiinae) da Colômbia e do Equador
}

\author{
Ubirajara R. Martins ${ }^{1,3}$ \& Maria Helena M. Galileo ${ }^{2,3}$ \\ 1. Museu de Zoologia, Universidade de São Paulo, Caixa Postal 42494, 04218-970 São Paulo, SP, Brasil. \\ 2. Museu de Ciências Naturais, Fundação Zoobotânica do Rio Grande do Sul, Caixa Postal 1188, 90001-970, Porto Alegre, RS, \\ Brasil. \\ 3. Bolsista do CNPq.
}

\begin{abstract}
Contribution to the Hemilophini (Cerambycidae, Lamiinae) of Colombia and Ecuador. New taxa described: from Ecuador, Quirimbaua gen. nov., type species Q. castroi (Napo); from Colombia: Icupima taua (Cauca), Adesmus murutinga and Tyrinthia dioneae (Valle del Cauca), Essosthrutella acatinga and Hemilomecopterus gen. nov., type species, H. alienus (Amazonas). New records for Colombia are presented for Olivensa mimula Lane, 1965, Tyrinthia paraba Martins \& Galileo, 1991, Amapanesia exotica (Martins \& Galileo, 1991), Sibapipunga beckeri (Martins \& Galileo, 1992), Juninia annulifera (Kirsch, 1889), Isomerida albicollis (Laporte, 1840), Adesmus diana (Thomson, 1860), A. pirauna Galileo \& Martins, 1999, Phoebe concinna White, 1856 and Leucophoebe albaria (Bates, 1872). A key to the species of Essosthrutella is added
\end{abstract}

KEYWORDS. Cerambycidae, Hemilophini, Neotropical, new records, new taxa.

\section{INTRODUÇÃO}

Esta contribuição complementa o artigo sobre os Hemilophini da Colômbia (GAlileo \& Martins, 2003) e acrescenta um táxon inédito procedente do Equador, remetido por Sergio Castro Martínez (Grupo de Estudios Ambientales, Santiago, Chile, GEAC). O material colombiano, enviado por Fernando Fernández e Cláudia Martínez, pertence às instituições: Instituto Alexander von Humboldt, Villa de Leyva (IAHC), Museo de Historia Natural, Santafé de Bogotá (MHNB) e Universidad Pedagógica Nacional, Santafé de Bogotá (UPNB). Outras instituições citadas no texto: Museu de Ciências Naturais, Fundação Zoobotânica do Rio Grande do Sul, Porto Alegre (MCNZ); Museu Nacional, Universidade Federal do Rio de Janeiro, Rio de Janeiro (MNRJ); Museu de Zoologia, Universidade de São Paulo, São Paulo (MZSP) e Muséum National d'Histoire Naturelle, Paris (MNHN).

\section{Quirimbaua gen.nov.}

Etimologia. Tupi, quirimbáua $=$ forte, alusivo ao aspecto geral robusto. Feminino.

Espécie-tipo, Quirimbaua castroi sp. nov.

Aspecto geral robusto. Mandíbulas com ápice acuminado. Fronte plana. Olhos inteiros. Lobos oculares superiores (fêmea) mais afastados entre si do que a largura de um lobo. Antenas com onze artículos, atingem o terço apical dos élitros. Escapo subcilíndrico, sem cicatriz. Flagelômeros basais sem franja compacta de pêlos. Antenômero III cerca de um terço mais longo do que o escapo; franja esparsa de pêlos curtos (apenas mais longos do que a largura do artículo) no lado interno. Antenômero IV com menos da metade do comprimento do III. Antenômeros V-XI com comprimentos subiguais. Protórax mais largo do que longo; constrições anterior e basal mais ou menos da mesma largura. Lados com gibosidade ao nível do meio. Élitros pubescentes, com lados paralelos até a curvatura apical, regularmente convexos, sem carena umeral; epipleuras sem franja de pêlos; extremidades arredondadas em conjunto. Procoxas salientes. Fêmures sublineares. Dente interno das unhas pouco mais curto que o externo.

Discussão. Quirimbaua apresenta um conjunto de caracteres muito peculiar que permite distingui-lo imediatamente. A ausência de carena umeral lembra espécies dos gêneros Essosthrutella Lane, 1972, Calocosmus Chevrolat, 1862 e Essostrutha Thomson, 1868. Entretanto, as espécies destes gêneros têm mandíbulas com ápice bífido. Em Calocosmus, cujas espécies são próprias das Antilhas, a pubescência corporal é muito esparsa e em diversas espécies os élitros têm cores metálicas.

O aspecto geral de Quirimbaua assemelha-se ao das espécies de Hilaroleopsis Lane, 1970, com algumas espécies ilustradas por MARTINS \& GALILEO (1992b:590, figs. 1-3). Nas espécies de Hilaroleopsis, cada élitro é provido de duas carenas, a umeral e uma segunda, paralela, na declividade lateral. Em Quirimbaua os élitros são completamente destituídos de carenas.

\section{Quirimbaua castroi sp. nov.} (Fig. 1)

Etimologia. O nome específico homenageia Sergio Castro-Martínez (GEAC), coletor do holótipo.

Cabeça preta; genas e área atrás dos olhos com pubescência amarelada. Antenas pretas. Pronoto coberto por pubescência esponjosa branco-amarelada; dorso da metade anterior com grande mancha transversal preta. Partes laterais do protórax com pubescência esponjosa branco-amarelada. Escutelo revestido por pilosidade amarelada. Élitros (fig. 1) com a metade anterior amarelada e a metade apical preta; as duas regiões separadas por linha transversal. Pernas pretas. Esternos mesotorácicos (exceto o processo mesosternal) pretos. Metasterno preto 
com mancha amarelada atrás das mesocoxas. Urosternitos amarelados.

Dimensões em mm. Comprimento total, 17,1; comprimento do protórax, 3,7; maior largura do protórax, 4,5; comprimento do élitro, 12,1; largura umeral, 6,0. Antenas: comprimento do escapo, 2,2; comprimento do antenômero III, 3,5; comprimento do antenômero IV, 1,5.

Material-tipo. Holótipo $\subsetneq$, EQUADOR, Napo: Napo, XI.2001-II.2002, S. Castro-Martínez col. (MZSP).

\section{Olivensa mimula Lane, 1965}

Olivensa mimula LANE, 1965:319; MonNé, 1995:41 (cat.).

A espécie foi descrita com base em duas fêmeas colecionadas em São Paulo de Olivença, Amazonas, Brasil, em 1883, por M. de Mathan. O holótipo foi depositado no MNHN e o parátipo no MZSP. O macho, ora examinado, é o terceiro exemplar conhecido da espécie e foi colecionado há mais de um século após os tipos.

Material examinado. COLÔMBIA, Amazonas: Amacayacu (Mata Mata, $03^{\circ} 23^{\prime} \mathrm{S}, 7^{\circ} 06^{\prime} \mathrm{W}, 150 \mathrm{~m}$ ), O’, 24.IV02.V.2000, A. Parente col., em armadilha Malaise (IAHC).

\section{Icupima taua sp. nov.}

(Fig. 2) corporal.

Etimologia. Tupi, tauá = amarelo, alusivo à cor

Cabeça revestida por pubescência alaranjada; pubescência preta na área que envolve o lado interno dos tubérculos anteníferos, a borda interna dos lobos oculares superiores e alarga-se até o occipício. Olhos inteiros. Lobos oculares superiores tão distantes entre si quanto a largura de um lobo. Lobos oculares inferiores arredondados, tão longos quanto as genas. Antenas pretas; antenômeros III e IV (fig. 2) engrossados com pêlos pretos, densos, em toda a superfície; base dos antenômeros III-VII com tegumento amarelado. Antenômeros V-XI com o mesmo comprimento de I-IV. Protórax mais largo do que longo. Lados do protórax com uma gibosidade muito pouco saliente, situada ligeiramente atrás do meio. Pronoto inteiramente recoberto por pubescência alaranjada, mais amarelada na metade basal dos lados. Élitros recobertos uniformemente por pubescência alaranjada; lados expandidos a partir de pequena distância da base; cada um com três costas apenas indicadas. Extremidades elitrais arredondadas. Pelo menos a ponta das asas membranosas, preta. Fêmures alaranjados. Tíbias e tarsos pretos. Face ventral do corpo alaranjada; lado inferior da metade apical dos metepisternos com mancha preta. Urosternito I amarelado; II-III gradualmente mais escuros nos lados, IV-V, pretos.

Dimensões em mm, fêmea. Comprimento total, 11,7; comprimento do protórax, 2,1; maior largura do protórax, 2,7; comprimento do élitro, 8,7; largura umeral, 3,3; maior largura de um élitro, 2,5.

Material-tipo. Holótipo $\subsetneq$, COLÔMBIA, Cauca: Parque Nacional Natural Isla Gorgona (Alto el Mirador, $02^{\circ} 58^{\prime} \mathrm{N}$, $78^{\circ} 11^{\prime} \mathrm{W}, 180 \mathrm{~m}$ ), 9-25.V.2000, H. Torres col. (IAHC).
Discussão. O gênero Icupima Martins \& Galileo, 1991 foi estabelecido para I. laevipennis (Gahan, 1892), cujos élitros são expandidos para os lados a partir do terço basal; cabeça preta com faixas longitudinais fulvas no meio e atrás dos lobos oculares superiores; protórax preto com larga faixa lateral fulva; élitros pretos, cada um com duas faixas transversais fulvas, uma na base e outra no meio (MARTins \& GALILEO, 1991b:560, fig. 9).

Icupima taua difere de I. laevipennis pelo colorido geral e pela expansão dos élitros iniciada logo após a base.

\section{Tyrinthia dioneae sp. nov.}

(Fig. 5)

Etimologia. O epíteto homenageia Dione Seripierri, bibliotecária do MZSP, a quem devemos inúmeras gentilezas.

Colorido geral da face dorsal amarelo-alaranjado; tegumento preto: tubérculos anteníferos, escapo, antenômeros (menos extremidades basal e apical), base das epipleuras, metade apical dos metepisternos, grande parte da face dorsal dos metafêmures, tíbias, tarsos, lados dos urosternitos; lados do metasterno mais acastanhados. Urosternitos, gradualmente mais enegrecidos, do primeiro ao quinto. Fronte com uma projeção a cada lado. Escapo, antenômeros III e IV (fig. 5) com franja de pêlos longos e pretos. Protórax com lados convergentes para a parte anterior. Lados do pronoto com faixa longitudinal de pubescência amarelada. Lados dos élitros em declive abrupto até o meio. Mesepisterno, metepimero e lados do metasterno pontuados.

Dimensões em mm. Comprimento total, 10,5; comprimento do protórax, 1,6; maior largura do protórax, 2,0; comprimento dos élitros, 7,7; largura umeral, 2,5.

Material-tipo. Holótipo ớ, COLÔMBIA, Valle del Cauca: Parque Nacional Natural Farallones de Cali (Anchicaya, $3^{\circ} 26^{\prime}$ N, 76º $48^{\prime}$ W, 650 m), 8.V-19.VI.2001, S. Sarria col., em armadilha Malaise (IAHC).

Discussão. Pela presença de pequenas projeções frontais, Tyrinthia dioneae pertence ao $1^{\circ}$ grupo (MARTINS \& Galileo, 1991c). Dentre as espécies deste grupo, assemelha-se mais a T. moroiuba Martins \& Galileo, 1991, igualmente descrita da Colômbia. Difere: franja de pêlos dos antenômeros III e IV muito mais esparsa e constituída por pêlos muito mais longos; curvatura basal do escapo menos acentuada; lados do pronoto com faixa longitudinal da base ao ápice; pontuação do pronoto constituída por pontos muito mais numerosos e mais profundos; epipleuras com mancha longitudinal, basal, preta; élitros relativamente longos; carena lateral dos élitros menos demarcada. Em T. moroiuba os pêlos dos antenômeros III e IV são muito densos e mais curtos; curvatura basal do escapo mais pronunciada; lados do pronoto com escassa pubescência no meio; pontuação do pronoto constituída por pontos menores e localizados nas depressões basal e apical; epipleuras sem mancha preta; élitros relativamente mais curtos (MARTINs \& GaLILEO, 1991c:822, fig. 8), com carena lateral manifesta na metade basal.

Embora T. picticornis Martins \& Galileo, 1991, 


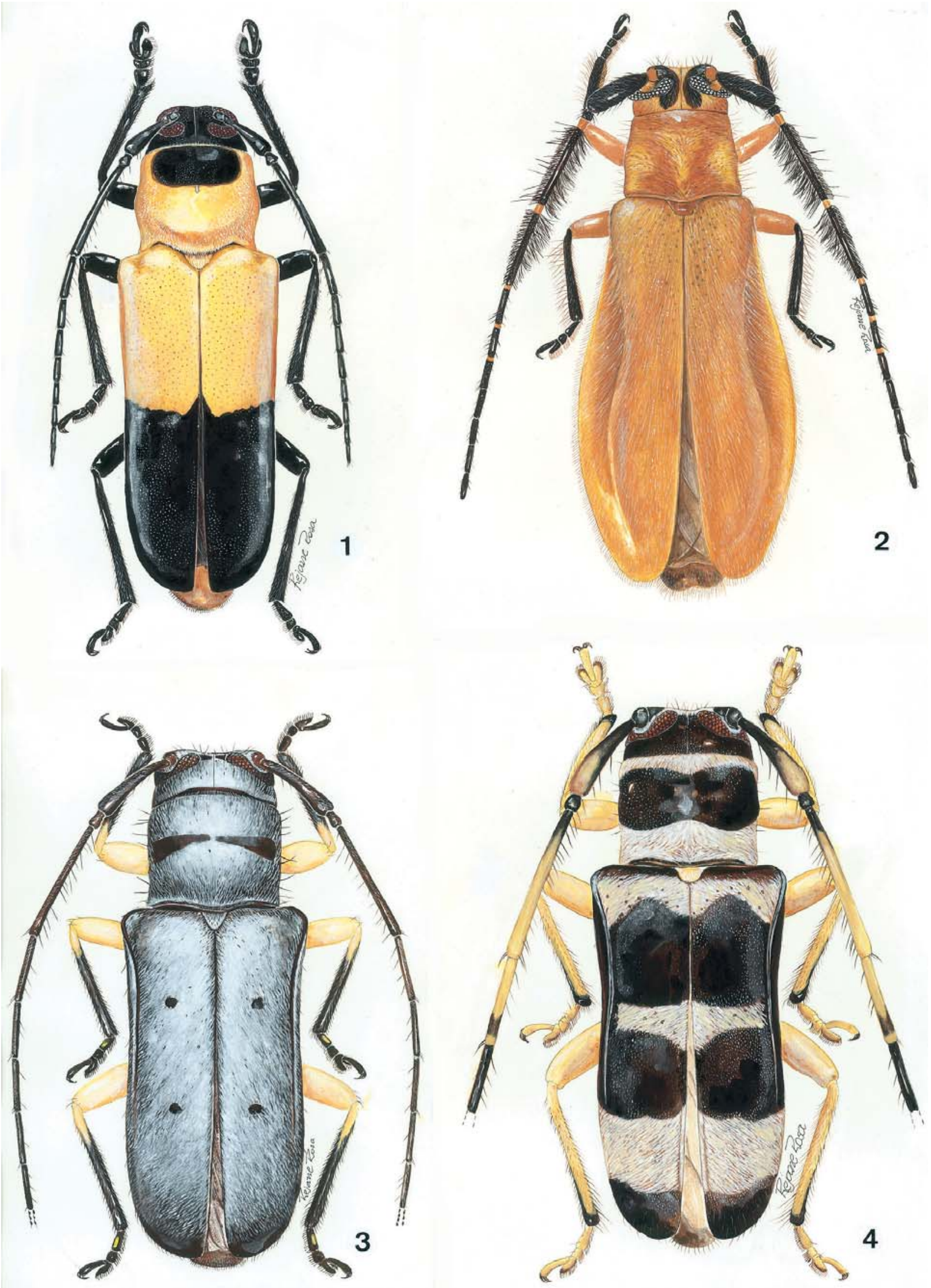

Figs. 1-4. 1, Quirimbaua castroi sp. nov., holótipo $\subsetneq$, comprimento $17,1 \mathrm{~mm} ; 2$, Icupima taua sp. nov., holótipo $\subsetneq$, comprimento $11,7 \mathrm{~mm} ; 3$, Adesmus murutinga sp. nov., holótipo \&, comprimento 12,6 mm; 4, Adesmus pirauna \&, comprimento 10,3 mm. 
descrita do Panamá, pertença ao $2^{\circ}$ Grupo por não ter projeções na fronte dos machos, também tem colorido geral amarelo-alaranjado e antenas aneladas. Tyrinthia dioneae separa-se pela presença de pêlos longos no lado interno do escapo e franja de pêlos mais longos nos antenômeros III-IV; pelo protórax com lados nitidamente convergentes para a parte anterior; pelo colorido preto nos tubérculos anteníferos; pela ausência de anel claro no terço apical do antenômero IV e pela base das epipleuras pretas. Em T. picticornis, a franja de pêlos no escapo e nos antenômeros III e IV é mais compacta e mais curta; o protórax tem lados subparalelos; a cabeça não tem colorido preto; o antenômero IV apresenta anel no terço apical e as epipleuras não são pretas.

\section{Tyrinthia paraba Martins \& Galileo, 1991}

Tyrinthia paraba Martins \& Galileo, 1991c:815, fig. 5; MonnÉ, 1995:10 (cat.).

Espécie descrita com base em duas fêmeas (Martins \& GaliLeo, 1991c) e bem variável em colorido. O exemplar ora examinado é o primeiro macho conhecido e tem diferenças com relação às fêmeas. A fronte apresenta duas gibosidades, pouco pronunciadas e arredondadas no topo; na cabeça a região ao redor dos côndilos antenais, grande parte do vértice e áreas atrás dos lobos oculares inferiores, pretas; escutelo com margens largamente pretas; élitros pretos e metafêmures alaranjados como no parátipo.

Material examinado. COLÔMBIA, Amazonas: Parque Nacional Natural Amacayacu (San Martín, $3^{\circ} 23^{\prime} \mathrm{S}, 70^{\circ} 6^{\prime} \mathrm{W}, 150$ m), ơ, 24.VIII-1.IX.2000, B. Amado col., em armadilha Malaise (IAHC).

\section{Essosthrutella acatinga sp. nov.}

(Fig. 6)

Etimologia. Tupi, aca $=$ chifre; tinga $=$ branco; alusivo aos antenômeros brancos.

Cabeça preta, genas e gula amareladas; revestida por pubescência esbranquiçada; depressão do vértice moderada. Lobos oculares superiores tão afastados entre si quanto quase o dobro da largura de um lobo. Antenas (fig. 6) atingem as pontas dos élitros, aproximadamente, no ápice do antenômero VII. Escapo alaranjado com a face ventral preta. Antenômeros III, base do IV, VII-XI, pretos; antenômeros IV (menos a base), V e base do VI, branco-amarelados. Antenômero III com cerca do dobro do comprimento do escapo, com franja de pêlos esparsa no lado interno. Antenômero IV mais longo do que o V. Antenômeros seguintes com comprimentos gradualmente decrescentes. Protórax alaranjado; disco pronotal preto, revestido por pubescência esbranquiçada. Gibosidade centro-basal do pronoto apenas indicada. Élitros pretos com quinto apical branco; friso sutural até o meio e friso marginal da base ao ápice, brancos; uma faixa de pubescência branca, levemente oblíqua em sentido ascendente da margem para a sutura e situada à frente do meio. Extremidades elitrais arredondadas e desarmadas. Pernas alaranjadas escurecidas na face dorsal das tíbias. Metafêmures não atingem as pontas dos élitros. Último urosternito com leve depressão transversal, anteapical.
Dimensões em mm, fêmea. Comprimento total, 7,68,4; comprimento do protórax, 1,4-1,7; maior largura do protórax, 1,8-2,1; comprimento do élitro, 5,3-6,4 ; largura umeral, 2,5-2,9.

Material-tipo. Holótipo $\subsetneq$, COLÔMBIA, Amazonas: Parque Nacional Natural Amacayacu (Mocagua, $3^{\circ} 41^{\prime}$ S, $70^{\circ} 15^{\prime} \mathrm{W}$, $150 \mathrm{~m})$, 26.II-12.III.2001, D. Chota col., armadilha Malaise (IAHC). Parátipo \&, COLÔMBIA, Amazonas: Parque Nacional Natural Amacayacu (San Martín, 346'S, 70²' $18^{\prime} \mathrm{W}, 150 \mathrm{~m}$ ), 15.X5.XI.2001, D. Chota col., armadilha Malaise (MZSP).

Discussão. O gênero Essosthrutella Lane, 1972 passa a reunir três espécies que se distinguem pelos caracteres apresentados na chave.

\section{Chave para as espécies de Essosthrutella}

1. Escapo com dorso alaranjado e face inferior preta; antenômeros pretos, exceto o IV (menos a base), $\mathrm{V}$, e extremo basal do VI, brancos; pronoto inteiramente preto; extremidades elitrais ocupadas por faixa branca (fig. 6). Colômbia (Amazonas)........... E. acatinga sp. nov.

Escapo e antenômeros unicolores; pronoto com mancha central preta; extremidades elitrais sem faixa branca................... 2

2(1). Coloração corporal alaranjada com pequenas manchas pretas nos élitros; pronoto revestido por pilosidade densa alaranjada com mancha central preta. Costa Rica. ............... ................ E. nevermanni Lane, 1972

Coloração geral preta; élitros com faixas transversais brancas; pronoto revestido por pilosidade branca com mancha central preta. Costa Rica, Panamá.......... E. notaticollis (Lane, 1973)

\section{Amapanesia exotica (Martins \& Galileo, 1991)}

Eulachnesia exotica Martins \& Galileo, 1991a:104, fig.1; Monné, 1995:54 (cat.).

Amapanesia exotica; Martins \& Galileo, 1996:189.

Esta espécie foi originalmente descrita com base numa fêmea procedente do Amapá, Brasil, alocada no gênero Eulachnesia e, posteriormente, transferida para o gênero Amapanesia Martins \& Galileo, 1996. Ora examinamos um macho que permite acrescentar alguns caracteres à descrição do gênero.

Macho. Fronte com uma elevação arredondada a cada lado. Antenas alcançam o sexto apical dos élitros e têm o mesmo comprimento que às das fêmeas. Carena elitral ultrapassa o meio dos élitros.

Material examinado. COLÔMBIA, Amazonas: Amacayacu (Caña Brava, 030' $\mathrm{S}, 70^{\circ} 03^{\prime} \mathrm{W}, 200 \mathrm{~m}$ ), ơ, 29.VIII.2001, M. Sharkey \& D. Campos col. (IAHC).

\section{Hemilomecopterus gen. nov.}

Etimologia. Combinação arbitrária de Hemilo (radical do nome da tribo) e Mecoptera, pelo aspecto da cabeça. Masculino.

Cabeça opistognata, mais larga que o protórax, com o vértice acentuadamente saliente e occipício longo, 

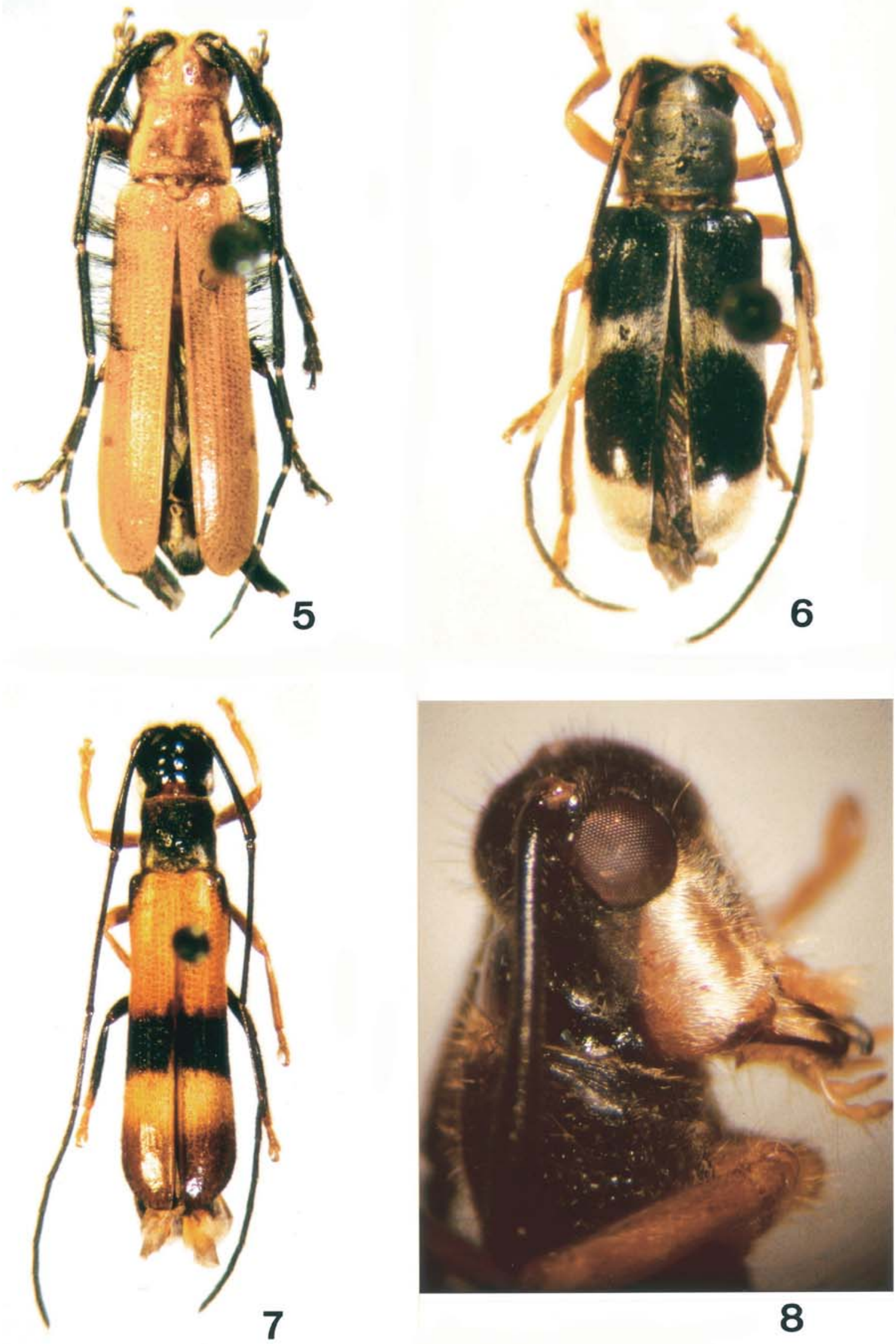

Figs. 5-7. 5, Tyrinthia dioneae sp. nov., holótipo o', comprimento 10,5 mm; 6, Essosthrutella acatinga sp. nov, holótipo \&, 8,4 mm; 7-8, Hemilomecopterus alienus sp. nov., holótipo §, comprimento 10,0 mm: 7, habitus, 8, cabeça lateral. 
fronte e genas muito prolongadas. Olhos acentuadamente estreitados entre os lobos; lobos oculares superiores tão distantes entre si quanto a largura de um lobo; lobos oculares inferiores redondos, metade do comprimento das genas. Antenas atingem o ápice dos élitros aproximadamente no ápice do antenômero VII. Ápice do antenômero IV atinge o terço apical dos élitros. Escapo, pedicelo, antenômeros III e IV apresentam franja esparsa no lado interno. Escapo ultrapassa o meio do protórax, esbelto e gradualmente engrossado para o ápice; mais longo que o antenômero IV e mais curto que o III. Protórax apenas mais largo que longo. Procoxas muito projetadas. Élitros alongados, comprimento igual a 3,6 vezes a largura umeral; sem carenas laterais; região sutural da base sem pêlos brancos; extremidades arredondadas e desarmadas. Tíbias anteriores mais longas que as médias. Ápice dos metafêmures apenas ultrapassa a borda apical do primeiro urosternito. Dente interno das unhas tarsais subigual em comprimento ao dente externo. Metasterno acentuadamente globoso. Urosternito V levemente intumescido.

Discussão. Hemilomecopterus assemelha-se a Olivensa Lane, 1965 e Cephalodina Bates, 1881, gêneros que apresentam cabeça desenvolvida e mais larga que o protórax. Difere de ambos pelo aspecto geral do corpo mais alongado; pela cabeça opistognata com a parte inferior muito alongada, pelo escapo longo que atinge o meio do protórax, pelo comprimento do escapo e dos antenômeros III e IV que, em conjunto, atingem o terço apical dos élitros. Em Olivensa e Cephalodina, o corpo é mais compacto, a cabeça é hipognata, a fronte tem comprimento normal, o escapo atinge a borda anterior do protórax e a soma dos comprimentos do escapo ao antenômero IV atinge a metade dos élitros. Hemilomecopterus difere de Olivensa pela ausência da faixa de pêlos sobre o friso sutural no terço anterior dos élitros.

\section{Hemilomecopterus alienus sp. nov. (Figs. 7, 8)}

Etimologia. Do latim, alienus = estranho, alusivo à forma da cabeça.

Cabeça (fig. 8) preta, exceto mancha no occipício, na região inferior da fronte e nas genas, avermelhadas. Genas cobertas por pubescência brilhante, esbranquiçada, que se prolonga pelos lados da cabeça até a mancha occipital. Antenas pretas. Protórax preto, revestido por pubescência amarelada, fina e esparsa; lados da base com faixa longitudinal curta de pubescência esbranquiçada mais compacta. Pronoto e partes laterais do protórax com pontos grossos e esparsos. Élitros (fig. 7) com a metade anterior amarelo-alaranjada exceto os úmeros que são pretos; faixa transversal, situada depois do meio, preta, seguida por outra faixa transversal de tegumento amarelado, recoberta por densa pubescência de mesma cor; quinto apical com tegumento castanhoavermelhado, recoberto por pubescência amarelada. Pernas anteriores e médias amareladas. Metafêmures pretos, exceto a face inferior. Metatíbias pretas com o ápice amarelado em pequena extensão. Metatarsos amarelados. Mesosterno preto com processo mesosternal amarelado. Mesepimeros, metepimeros e lados do metasterno, pretos; centro do metasterno, urosternitos I a III amarelados; urosternito IV e V castanhos.

Dimensões em mm. Comprimento total, 10,0; comprimento do protórax, 1,6; maior largura do protórax, 1,8; comprimento do élitro, 6,8; largura umeral, 1,9. Comprimento dos antenômeros: escapo, 2,5; III, 3,5; IV, $2,1$.

Material-tipo. Holótipo $\subsetneq$ COLÔMBIA, Amazonas: Parque Nacional Natural Amacayacu (San Martín, $3^{\circ} 46^{\prime}$ 'S, $70^{\circ} 18^{\prime} \mathrm{W}, 150$ m), 15.X-5.XI.2001, D. Chota col., armadilha Malaise (IAHC).

\section{Sibapipunga beckeri (Martins \& Galileo, 1992)}

Juninia beckeri MARTINS \& GALILEO, 1992a:577.

Sibapipunga beckeri; Martins \& GALILEO, 1993:110, figs. 2, 3; Monné, 1995:37 (cat.).

Esta espécie era conhecida da Costa Rica e do Equador e ora registra-se para a Colômbia.

Material examinado. COLÔMBIA, Valle del Cauca: Quebrada El Pital (Rio Calima), \&, 1.VIII.1981, D. Torres col. (MHNB).

\section{Juninia annulifera (Kirsch, 1889)}

Amphyonicha annulifera KIRSCH, 1889:44.

Adesmus annulifer; Aurivillius, 1923:589 (cat.).

Juninia annulifera; Martins \& GaliLeo, 1993:111; Monné, 1995:37 (cat.).

Juninia leechi Lane, 1966:247; Martins \& Galileo, 1993:111 (sin.).

Juninia annulifera foi originalmente descrita de Huamboya, cordilheira equatoriana definida por BROwN (1941): “Huamboya, Santigo-Zamora, ca. 143'S, $78^{\circ} 20^{\prime} \mathrm{W} ; 1500-4000 \mathrm{~m}$. The ridge extending eastward from Cerro Altar into the Oriente. The extreme upper slopes are paramo. The lower slopes are densely clothed with forest, temperate and sub-tropical. At the eastern foot lies the Amazonian tropical jungle." O nome atual da província é Morona Santiago.

LANe (1966) descreveu Juninia leechi $(=J$. annulifera) baseado em duas fêmeas da Província de Junín no Peru. Martins \& GaliLeo (1993) citaram-na para o Equador, Cañar: Azogues, fundamentados numa fêmea do MNRJ. O material ora examinado amplia a distribuição para a Colômbia.

Material examinado. COLÔMBIA, Valle del Cauca: Quebrada El Pital (Rio Calima), \&, 20.III.1981, R. Torres col. (MHNB).

\section{Isomerida albicollis (Laporte, 1840)}

Hemilophus albicollis LAPORTE, 1840:488.

Isomerida albicollis; BATES, 1866:373; MonnÉ \& Hovore, 2003 (cat.).

Material examinado. COLÔMBIA, Amazonas: Parque Nacional Natural Amacayacu (San Martín, 346’S, 70¹8'W, 150 m), §, 10-18.X.2000, B. Amado col., armadilha Malaise (IAHC).

\section{Adesmus diana (Thomson, 1860)}

Amphionicha Diana Thomson, 1860:65.

Hemilophus diana; Gemminger \& Harold, 1873:3209 (cat.).

Adesmus diana; Aurivillius, 1923:569 (cat.); Monné, 1995:23 (cat.); Galileo \& Martins, 1999a:82, 93, fig. 31. 
Adesmus diana foi originalmente descrita da "Guiana interior". BATES (1866:426) assinalou-a para o Brasil (Pará: Tapajós) e para a Guiana Francesa. GALILEo \& MARTINS (1999a) registraram-na para o Pará: Santarém.

Examinamos um casal procedente da Colômbia que tem no meio da fronte, nos dois sexos, um pequeno tubérculo. A pubescência branca compacta sobre os urosternitos é diferente nos dois sexos: a fêmea tem duas manchas pequenas nos lados do meio; o macho apresenta no urosternito I quatro manchas, duas pequenas, de cada lado, na orla lateral e duas mais centrais próximas à borda posterior; urosternito II com duas manchas, maiores, de contornos irregulares, nos lados do meio; urosternito III com duas manchas, bem pequenas, próximas da margem lateral.

Material examinado. COLÔMBIA, Casanare: Yopal (W para Aguazul), f, 16-18.VIII.1997, D. Vergara col. (MZSP). Meta: Acacías (Vereda Monte Bello), o', 15-17.XI.1997, D. Vergara col. (UPNB).

\section{Adesmus murutinga sp. nov. (Fig. 3)}

Etimologia. Tupi, murutinga $=$ branco, alusivo ao colorido corporal.

Cabeça, antenas, pronoto, úmeros, 3/4 distais das tíbias e tarsos com tegumento preto; élitros (exceto manchas pretas), face ventral do corpo, palpos, coxas, trocanteres, fêmures e quarto basal das tíbias com tegumento amarelado. Cabeça revestida por densa pubescência branca com uma mancha preta, triangular no meio da fronte; uma faixa preta, estreita, transversal, entre os lobos oculares superiores e faixa preta, estreita, transversal no occipício. Meio do pronoto com faixa preta, transversal, que não chega até os lados do protórax e se estreita para o meio (fig. 3). Em cada élitro manchas ou faixas pretas: uma arredondada, dorsal, pequena, no terço anterior; uma outra, semelhante à primeira, no nível do terço posterior; uma mancha, alongada no quarto anterior sob os úmeros e junto à margem; faixa transversal estreita ocupa as extremidades. Esternos torácicos densamente revestidos por pubescência branca. Urosternitos II-IV com pubescência branca, exceto faixa acastanhada na metade anterior; urosternito $\mathrm{V}$ inteiramente castanhoamarelado. Lobos oculares inferiores com o mesmo comprimento das genas. Antenômero III com pêlos muito esparsos no lado interno. Carena umeral alcança o terço apical dos élitros.

Dimensões em mm, fêmea. Comprimento total, 12,6; comprimento do protórax, 2,9; maior largura do protórax, 3,4; comprimento do élitro, 9,1; largura umeral, 4,7.

Material-tipo. Holótipo $\&$, COLÔMBIA, Valle del Cauca: Parque Nacional Natural Farallones de Cali $\left(3^{\circ} 26^{\prime} \mathrm{N}\right.$, $\left.76^{\circ} 48^{\prime} \mathrm{W}, 730 \mathrm{~m}\right), 9 . \mathrm{V}-18$.VII.2000, S. Sarria col., em armadilha Malaise (IAHC).

Discussão. O colorido geral de Adesmus murutinga, com pubescência corporal predominantemente branca, lembra o de A. hemispilus (Germar, 1821), A. phoebinus (Aurivillius, 1900), A. brunneiceps (Aurivillius, 1920) e A. stephanus (Aurivillius, 1900). Nestas espécies, com exceção de $A$. hemispilus, os élitros não apresentam manchas escuras e o pronoto tem faixas escuras longitudinais. Em A. hemispilus, que ocorre no Brasil (Mata Atlântica), no Paraguai e na Argentina (Misiones), os lobos oculares superiores têm 2,5 vezes o comprimento das genas; a disposição das manchas na cabeça, no protórax e nos élitros é diferente (Galileo \& Martins, 1999a:104, fig. 16) e os fêmures, a base das tíbias e a face ventral são pretos.

\section{Adesmus pirauna Galileo \& Martins, 1999 (Fig. 4)}

Adesmus pirauna Galileo \& Martins, 1999b:113, fig 4.

Cabeça preta; fronte (exceto região central) e genas cobertas por pubescência branca. Escapo preto com lado externo da metade apical alaranjado; pedicelo preto; antenômero III amarelado, exceto pequena região basal, preta; antenômero IV brancoamarelado menos anel anteapical, acastanhado; antenômero V preto (fig. 4). Antenômeros VI a XI faltam. Protórax revestido por pubescência branca compacta; pronoto com larga faixa preta, transversal, com a maior parte à frente do meio. Escutelo recoberto por pubescência branca compacta. Élitros pretos com faixas transversais brancas: uma junto à declividade basal, uma no meio e uma, mais larga, no meio do terço apical. Pernas amareladas, exceto as extremidades das tíbias, pretas. Face ventral recoberta por pubescência branca; mesosterno, centro do metasterno, base dos urosternitos II a IV glabros. Lobos oculares inferiores pouco mais longos que as genas. Carena umeral alcança o quarto apical dos élitros.

Dimensões em mm. Comprimento total, 10,3; comprimento do protórax, 2,3; maior largura do protórax, 2,6; comprimento do élitro, 7,3; largura umeral, 3,6.

Material examinado. COLÔMBIA, Valle del Cauca: Parque Nacional Natural Farallones de Cali $\left(3^{\circ} 26^{\prime} \mathrm{N}, 76^{\circ} 48^{\prime} \mathrm{W}\right.$, $730 \mathrm{~m}$ ), f, 9.V.-18.VII.2000, S. Sarria col., em armadilha Malaise (IAHC).

Discussão. Adesmus pirauna foi coletada no mesmo local e data que A. murutinga e, inicialmente, suspeitouse tratar-se da mesma espécie. Difere pela colorido corporal (figs. 3, 4), pelo escapo mais robusto e de cor diferente, pelos antenômeros III, IV e tarsos, brancoamarelados. Adesmus pirauna assemelha-se também, pelo colorido, a A. nigrocinctus (Gahan, 1889); distingue-se pela faixa preta no pronoto, pela cor preta do escapo, do pedicelo e do antenômero $\mathrm{V}$; pelo número de faixas brancas nos élitros; pelos dois terços anteriores das epipleuras inteiramente pretos. Em A. nigrocinctus não ocorre faixa preta no pronoto (GALILEO \& Martins 1999a:105, fig. 18); o escapo, o pedicelo e os antenômeros III e IV são amarelados e o antenômero V possui um anel basal amarelado; os élitros têm apenas duas faixas brancas, largas; as epipleuras são pretas na base e brancas até o meio.

\section{Phoebe concinna White, 1856}

Phoebe concinna White, 1856:408; Monné \& Hovore, 2003 (cat.). 
Material examinado. COLÔMBIA, Caquetá: San José de Fragua (1²0’N, 76º6’W, 1270 m), f, 9-13.IX.2000, E. González col., armadilha Malaise (IAHC).

\section{Leucophoebe albaria (Bates, 1872)}

Amphionycha albaria BATES, 1872:230.

Hemilophus albarius; GeMminger \& HAROLD, 1873:3208 (cat.). Phoebe albaria; BAtes, 1881:215; Monné, 1995:34 (cat.).

Leucophobe albaria; Martins \& Galileo, 1998:435.

Material examinado. COLÔMBIA, Cundinamarca: W Villeta-Tobia (790 m), f, 13.XI.1994, G. Muñoz col. (UPMB); Tolima: Mariquita (W Catarata de Medina), 2 ऽ, 15-16.XI.2000, L. Castañeda, L. Sánches \& E. Pardo col. (MCNZ, MZSP).

Agradecimentos. À desenhista Rejane Rosa pelas ilustrações e a Luciano de Azevedo Moura pelas fotografias, ambos do MCNZ.

\section{REFERÊNCIAS BIBLIOGRÁFICAS}

Aurivillius, C. 1923. Coleopterorum catalogus, pars 74, Cerambycidae: Lamiinae. II. Berlin, W. Junk. p.323704.

BAtes, H. W. 1866. Contributions to an insect fauna of the Amazon Valley. Coleoptera: Longicornes. Annals and Magazine of Natural History, London, (3)17:367-373, 425-435.

1872. On the longicorn Coleoptera of Chontales, Nicaragua. Transactions of the Entomological Society of London, London, 1872:163-238.

1881. Biologia Centrali-Americana. Coleoptera, Longicornes. London, British Museum (Natural History). v.5, p.153-224, est.12-15.

Brown, F. M. 1941. A gazetteer of entomological stations in Ecuador. Annals of the Entomological Society of America, New York, 34:809-851.

Galileo, M. H. M. \& Martins, U. R. 1999a. O gênero Adesmus (Coleoptera, Cerambycidae, Lamiinae, Hemilophini). Iheringia, Sér. Zool., Porto Alegre, (86):77-116.

- 1999b. Sobre alguns Lamiinae (Coleoptera, Carambycidae) da Colômbia com garras tarsais apendiculadas e bífidas. Papéis Avulsos de Zoologia, São Paulo, 41(7):105-118.

_. 2003. Cerambycidae (Coleoptera) da Colômbia. VI. Lamiinae com unhas tarsais divaricadas ou bífidas. Iheringia, Sér. Zool., Porto Alegre, 93(3):225-270.

Gemminger, M. \& Harold, E., von. 1873. Catalogus coleopterorum hucusque descriptorum synonymicus et systematicus. Monachii. v.10, p.2989-3232.

KIRSCH, T. F. 1889. Coleopteren gesammelt in den Jahren 18681877 auf einer reise durch Süd Amerika von Alphons Stübel. Abhandlungen und Berichte des König Zoologischen und antropologisch-etnographischen Museums zu Dresden, Dresden, 4:1-58.
Lane, F. 1965. Cerambycoidea Neotropica nova VI. Studia Entomologica, Petrópolis, 8(1-4):269-336.

1966. Novos gêneros e espécies de Hemilophini I. Gêneros com antenas de 12 artículos. Papéis Avulsos do Departamento de Zoologia, São Paulo, 18(21):245249.

Laporte, F. L. N. (Comte de Castelnau). 1840. Histoire Naturelle des Insectes Coléoptères. Paris. v. 2, $563 \mathrm{p}$.

Martins, U. R. \& Galileo, M. H. M. 1991a. Longicórneos do Museu Paraense Emílio Goeldi II. Descrições em Aerenicini e Hemilophini (Coleoptera, Cerambycidae). Boletim do Museu Paraense Emílio Goeldi, Sér. Zool., Belém, 7(2):103-106.

1991b. Subdivisão do gênero Lycidola Thomson, 1864 (Coleoptera, Cerambycidae, Lamiinae, Hemilophini). Revista Brasileira de Entomologia, São Paulo, 35(3):553-565.

1991c. O gênero Tyrinthia Bates, 1866 e gêneros afins (Coleoptera, Cerambycidae, Lamiinae, Hemilophini). Revista Brasileira de Entomologia, São Paulo, 35(4):813-824.

- 1992a. Gêneros de Hemilophini (Coleoptera, Cerambycidae, Lamiinae), com antenas de doze artículos. Revista Brasileira de Entomologia, São Paulo, 36(3):575-579.

_. 1992b. O gênero Hilaroleopsis Lane, 1970 e descrições de novos táxons em Hemilophini (Coleoptera, Cerambycidae, Lamiinae). Revista Brasileira de Entomologia, São Paulo, 36(3):589-596.

1993. Descrição de novos táxons com antenas de doze artículos, transferência de espécies de Adesmus Lepeletier \& A.-Serville, 1825 e sinônimos (Coleoptera, Cerambycidae, Lamiinae, Hemilophini). Iheringia, Sér. Zool., Porto Alegre, (74):109-116.

1996. Divisão de Eulachnesia Bates, 1872 e descrição de novos táxons (Hemilophini). Revista Brasileira de Entomologia, São Paulo, 40(2):181-196.

1998. Gêneros de Hemilophini (Coleoptera, Cerambycidae) semelhantes a Phoebe Audinet-Serville, 1835. Revista Brasileira de Entomologia, São Paulo, 41(2-4):431437.

Monné, M. A. 1995. Catalogue of the Cerambycidae (Coleoptera) of the Western Hemisphere. Part XX. São Paulo, Sociedade Brasileira de Entomologia. 120 p.

Monné, M. A. \& Hovore, F. T. 2003. Checklist of the Cerambycidae and Disteniidae (Coleoptera) of the Western Hemisphere. Eletronic version 2003. (www.hovore.com)

Thоmson, J. 1860. Essai d'une classification de la famille des cérambycides et materiaux pour servir a une monographie de cette famille. Paris. $404 \mathrm{p}$.

White, A. 1856. Descriptions of some coleopterous insects in the collection of the British Museum, hitherto apparently unnoticed. Proceedings of the Zoological Society of London, London, 24:406-410. 